Creating Productive and Upcoming Sport Education Profesional Hmzanwadi University

Vol.3, No.2, Desember 2020, Hal. 71-80

e-ISSN 2614-8781

\title{
PROFIL OLAHRAGA TRADISIONAL SANJASIO
}

\author{
Delvi Kristanti Liloi ${ }^{1}$, Yuniva Yasin ${ }^{2}$ \\ email: delvi_liloi@yahoo.com ${ }^{1}$,yuniva.a212@gmail.com² \\ 1 Program Pendidikan Jasmani Kesehatan dan Rekreasi, Fakultas Keguruan Ilmu Pendidikan, Universitas \\ Tadulako, ${ }^{2}$ SMA Negeri 2 Sindue Tombusabora
}

\begin{abstract}
Abstrak
Permasalahan dalam penelitian ini adalah Bagaimana profil olahraga tradisional Sanjasio di Kecamatan Sindue. Adapun tujuan dari penelitian ini adalah untuk mengetahui profil olahraga tradisional Sanjasio di Kecamatan Sindue. Sumber data dalam penelitian ini adalah data hasil wawancara dan data tertulis. Tehnik pengumpulan data yang digunakan yaitu pengamatan langsung pada objek peneltian (observasi), wawancara (interview), dan (dokumentasi). Untuk menganalisis data penulis menggunakan beberapa cara diantaranya: (1) reduksi data. (2) penyajian data, dan (3) verifikasi data atau penarikan kesimpulan. Hasil dari penelitian ini menunjukan bahwa olahraga tradisional Sanjasio tercipta berdasarkan sejarah perlawanan suku Kaili Njedu di Pinggiran Pantai Sindue melawan tentara Balangingi (bajak laut). Olahraga tradisional Sanjasio adalah bentuk olahraga tempo dulu oleh masyarakat suku Kaili Njedu disaat panen telah tiba dikenal dengan istilah Kailinya Novonju (tradisi sebelum panen) atau Nomparoya (tradisi sesudah panen). Pemain Sanjasio berjumlah 18 orang, masing-masing regu terdiri dari 9 orang pemain, dan wasit berjumlah 5 orang, pemain musik berjumlah 2 orang, yaitu pemain Gendang dan Lalove, sebelum permainan dimulai ada nyanyian tradisi Kaili sekaligus pemanasan, durasi permainan selama 15 menit, menang tidaknya suatu permainan ditentukan dari jumlah batu yang dimasukan ke kotak poin.
\end{abstract}

Kata Kunci: Olahraga tradisional Sanjasio

\begin{abstract}
Abstrack
The problem in this study is how the profile of traditional Sanjasio sports in Sindue District. The purpose of this study was to determine the profile of traditional Sanjasio sports in Sindue District. Sources of data in this study are data from interviews and written data. Data collection techniques used are direct observation of the object of research (observation), interview (interview), and (documentation). To analyze the data, the authors used several methods including: (1) data reduction. (2) presentation of data, and (3) verification of data or drawing conclusions. The results of this study indicate that the traditional sport of Sanjasio was created based on the history of the resistance of the Kaili Njedu tribe on the edge of the Sindue Beach against the Balangingi army (pirates). The traditional sport of Sanjasio is a form of sport in the past by the Kaili Njedu tribe when the harvest has arrived known as Kailinya Novonju (tradition before harvest) or Nomparoya (tradition after harvest). There are 18 Sanjasio players, each team consisting of 9 players, and 5 referees, 2 music players, namely Gendang and Lalove players, before the game starts there is a traditional Kaili singing as well as a warm-up, the
\end{abstract}


game duration is 15 minutes, whether a game is won or not is determined by the number of stones that are added to the points box.

Keywords: Traditional Sanjasio sports

\section{A. Pendahuluan}

Dalam Abd. Rahman Azahari, 2016) adalah olahraga yang berkembang dari suatu jenis permainan daerah tertentu sehingga menjadi jenis olahraga yang bersifat asli/tradisional dan berkembang di daerah lain sebagai salah satu kekayaan bangsa. Olahraga tradisonal merupakan sebuah kegiatan olahraga yang memiliki keunikan tersendiri, jika dibandingkan dengan bentuk atau cabang-cabang olahraga yang lain. Unik, karena olahraga tradisional tidak terlepas dari tradisi yang berlaku di daerah masing-masing .Olahraga tradisional menurut Hatta dkk, (2002) menyatakan bahwa, "Olahraga tradisional adalah bentuk kegiatan olahraga yang berkembang dari suatu kebiasaan masyarakat tertentu, yang pada perkembangannya selanjutnya dijadikan sebagai jenis permainan yang memiliki ciri khas suatu daerah serta disesuaikan dengan tradisi budaya setempat. Menurut Ajun Khamdani (2010:89), olahraga tradisional lahir dan berkembang di bumi nusantara memiliki nilai pendidikan yang tinggi guna membangun akhlak, jiwa, dan raga bagi pelakunya. Para pelaku olahraga tradisional dapat membangun berbagai nilai seperti kesegaran jasmani, kesehatan, percaya diri, nilai sosial, dan rasa empati terhadap orang lain. Olahraga tradisional yang ada, pada saat ini bisa dikatakan hampir tinggal kenangan bahkan generasi saat ini mulai banyak meninggalkan olahraga tersebut, hal ini disebabkan oleh maraknya perkembangan olahraga modern. Olahraga tradisional harus memiliki dua persyaratan yaitu "olahraga" dan "tradisional" baik dalam memiliki tradisi yang sudah berkembang selama beberapa generasi, maupun dalam arti sesuatu yang terkait dengan tradisi budaya suatu bangsa secara lebih luas (Bambang Laksono, dkk, 2012:1). Menurut Te Bu (2011:5) olahraga tradisional adalah warisan budaya nasional dan pembangunan proyek sistematis, yang tidak hanya melibatkan lapangan olahraga tetapi juga membutuhkan suasana yang dibangun oleh lingkungan besar masyarakat. Olahraga tradisional Sanjasio diangkat dari sejarah perlawanan suku Kaili Njedu dipinggiran pantai Sindue melawan tentara Balangingi (bajak laut). Tentara Balangingi dikenal sangat ganas bahkan tak segan-segan membunuh dan merampok harta penduduk yang menetap dipinggiran pantai Sindue. Disuatu ketika tentara Balangingi mengadakan penyerbuan pada malam hari dengan senjata terhunus, pedang, parang, dan pisau. Maksud dan tujuan gerombolan Balangingi adalah untuk membunuh dan merampok harta penduduk pinggiran pantai Sindue. (Lahmudin, 2006).

\section{B. Metode}

Dalam penelitian ini penulis menggunakan metode penelitian kualitatif deskriptif. Penelitian kualitatif deskriptif adalah penelitian yang menggambarkan keadaan alamiah sebuah variabel, gejala ataupun keadaan (Burhan Bungin, 2001:48). Data kulalitatif diperoleh melalui berbagai teknik pengumpulan data misalnya dari hasil wawancara, sumber datanya diperoleh dari beberapa informan di Desa Toaya, Kecamatan Sindue, Kabupaten Donggala. Dalam sebuah penelitian, subjek penelitian memiliki peran yang sangat strategis karena pada subjek penelitian, itulah data tentang variabel yang penelitian akan diamati. Adapun subyek dalam penelitian ini, adalah penemu olahraga tradisional Sanjasio Lahmudin L. Tindavera, pemain olahraga 
Creating Productive and Upcoming Sport Education Profesional Hmzanwadi University

Vol.3, No.2, Desember 2020, Hal. 71-80

e-ISSN 2614-8781

tradisional Sanjasio Ricvain Abdul Gani, toko masyarakat Husen Bjihana. Adapun instrument yang digunakan Dalam penelitian ini: 1) Pedoman wawancara, 2) kamera, 3) alat perekam berupa HP, 4) alat tulis. Teknik pengumpulan data yang digunakan dalam penelitian ini adalah, Observasi, wawancara dan dokumentasi.

\section{Hasil dan Pembahasan Sejarah olahraga tradisional Sanjasio}

Olahraga tradisional Sanjasio diangkat dari sejarah perlawanan Suku Kaili Njedu di Pinggiran Pantai Sindue melawan tentara Balangingi (bajak laut). Tentara Balangingi dikenal sangat ganas bahkan tak segan-segan membunuh dan merampok harta penduduk yang menetap di Pinggiran Pantai Sindue. Disuatu ketika tentara Balangingi mengadakan penyerbuan pada malam hari dengan senjata terhunus, pedang, parang, dan pisau. Maksud dan tujuan gerombolan Balangingi adalah untuk membunuh dan merampok harta penduduk pinggiran Pantai Sindue. (Lahmudin, 2006). Sekalipun sudah terdesak dalam pengepungan dan penyerangan masih ada yang lolos. Dari situlah penduduk Pinggiran Pantai (Suku Kaili Njedu) mengatur dan mempersiapkan perlawanan ketika diserang kembali oleh gerombolan bajak laut (Balangingi). Mereka semakin giat meningkatkan strategi (latihan) untuk persiapan menyerang tentara Balangingi (Bajak laut). Mereka (Suku Kaili Njedu) membuat lubang-lubang dipinggiran Pantai dan bola api yang terbuat dari karung, maksud dari lubang-lubang dan bola api tersebut adalah bentuk perlawanan Suku Kaili Njedu terhadap tentara Balangingi, begitu melihat pinggiran Pantai sudah terbakar tentara Balangingi mengira bahwa suda ada perampok yang mendahului mereka, merekapun pergi meninggalkan Suku Kaili Njedu. Sekalipun tentara Balangingi tidak datang lagi menyerang, Suku Kaili Njedu tetap melakukan latihan ketangkasan, dari kebiasaankebiasaan malatih diri, akhirnya mereka tetapkan Sanjasio sebagai bentuk permainan yang rutin dilakukan setiap tahunnya.

Olahraga Sanjasio adalah bentuk olahraga tempo dulu oleh masyarakat Suku Kaili Njedu disaat panen telah tiba dikenal dengan istilah Kailinya Navonju atau Nomparoya. Begitu mereka selesai melakukan ritualnya, mulailah mereka turun dari lereng pedalaman menuju Pantai atau pemukiman warga yang sama (Suku Kaili Njedu). Mereka melakukan pertandingan olahraga tradisi diantaranya olahraga Sanjasio ini. Olahraga ini memiliki ciri tersendiri karena di samping menggunakan ketangkasan dan keahlian mengatur langka, memasukan kaki ke dalam lobang yang sudah siap dengan bola api, juga memiliki nilai-nilai seni dan budaya tradisi Kaili, namun bentuk olahraga ini sudah diambang kepunahan. Sanjasio terdiri dari dua Suku kata yaitu Sanja dan Sio, Sanja artinya berbanjar sedangkan Sio artinya sembilan. Olahraga ini hingga dikatakan Sanjasio karna masing-masing regu terdiri dari sembilan orang pemain. Kedua regu tersebut masing-masing melakukan lompatan kesembilan lubang, lubang-lubang itu dibuat secara berbanjar disesuaikan dengan banjar pemain.

Nilai budaya, dan nilai sosial dalam olahraga tradisional Sanjasio

1. Nilai budaya

Nilai budaya yang terkandung dalam olahraga tradisional Sanjasio antara lain adalah: Kebersamaan, ketelitian, gotong royong. Nilai kebersamaan tercermin dari berkumpulnya masyarakat suku Kaili Njedu disaat panen telah tiba dikenal dengan istilah kailinya Novonju atau Nomparoya untuk wujud kebersamaan dalam hidup bersama didalam lingkungannya. Nilai ketelitian tercermin dari awal permainan olahraga tradsional Sanjasio, dimana memerlukan persiapan baik sebelum pertandingan maupun persiapan latihan. 
Persiapan itu tidak hanya menyangkut peralatan tetapi juga tempat, waktu, wasit dan peserta. Nilai gotong royong tercermin dari keterlibatan masyarakat dalam penyelenggaraan olahraga tradisional sanjasio, mereka saling membantu demi terlaksananya olahraga tersebut.

2. Nilai Sosial

Nilai sosial adalah nilai yang dianut oleh suatu masyarakat mengenai apa yang dianggap baik dan apa yang dianggap buruk oleh masyarakat. Dikatakan baik atau buruk, pantas atau tidak pantas harus melalui proses menimbang. Hal ini tentu sangat dipengaruhi oleh kebudayaan yang dianut masyarakat. tak heran apabila antara masyarakat yang satu dan masyarakat lain terdapat perbedaan tata nilai. Sebagaimana suku-suku lainnya, suku Kaili juga mempunyai adat istiadat sebagai bagian kekayaan budaya didalam kehidupan sosial, Penyelenggaraan Olahraga tradisional Sanjasio biasanya dilaksanakan pada saat panen tiba. Unsur fisik dalam olahraga tradisional SanjasioMengapa Sanjasio sampai dikatakan sebagai olahraga? Karena ada unsur fisik yang dominan dalam olahraga tradisonal sanjasio, unsur fisik dapat diuraikan sebagai berikut:

3. Unsur Keseimbangan

Unsur keseimbangan sangat dominan dalam permainan olahraga tradisional Sanjasio, disaat peserta akan melakukan lompatan dari satu lubang kelubang yang lain dengan satu kaki peserta akan mempertahankan posisi beban berat tubuh agar tidak terjatuh dan menginjak lingkaran api. Dalam keseimbangan statis, ruang gerak biasanya sangat kecil, misalnya berdiri di atas dasar yang sempit (balok keseimbangan dan rel kereta api), melakukan handstand, dan mempertahankan keseimbangan setelah berputar ditempat. Keseimbangan dinamis (dynamic balance), adalah kemampuan untuk bergerak dari satu titik atau ruang dengan mempertahankan keseimbangan, misalnya menari, latihan kuda-kuda atau palang sejajar, sky air, skating, sepatu roda, dan lainnya. Pada olahraga tradisional Sanjasio keseimbangan yang dipakai adalah keseimbangan dinamis. Keseimbangan ini berperan ketika telapak kaki berada dipapan start atau papan tumpuan dan pada saat pemain melakukan loncatan dari lubang-kelubang.

4. Unsur Kecepatan Berlari

Unsur berlari sangat dominan dalam permainan olahraga tradisional Sanjasio, Kemampuan berlari juga membutuhkan kemampuan sprint yang tinggi. Hal ini sering terjadi pada saat pemain mulai berlari dan meloncat dari lubang kelubang loncatan, dan berlari kembali kebarisan paling belakang teman satu regu/kelompok. Kecepatan berlari sangat menentukan menang dan tidaknya sautu permainan. Kecepatan adalah kemampuan untuk melakukan gerakan-gerakan secara berulang, cepat dalam waktu yang sesingkatsingkatnya, atau kemampuan untuk menempuh jarak dalam waktu yang sesingkatsingkatnya

\section{Alur permainan olahraga tradisional Sanjasio}

Sebelum permainan dilaksanakan terlebih dahulu peserta melakukan pemanasan, diringi dengan lagu Kanara, wasit mengambil posisi masing-masing, kemudian wasit mengatur kedua regu agar siap diposisi masing-masing, wasit satu sebagai pemberi aba-aba ketika permainan dimulai (wasit start). Wasit dua dan tiga bertugas sebagai penjaga lubang, dimana wasit dua dan tiga melihat lompatan pemain apakah lompatan pemain sah atau up. Kemudian wasit empat dan lima bertugas sebagai penjaga kotak poin, dimana wasit empat dan lima bertugas menghitung batu poin yang dimasukan oleh kedua regu pemain olahraga tradisonal Sanjasio, apabila batu tidak masuk kekotak poin, maka poin tidak akan terhitung, walaupun lompatan dianggap sah. 


\section{Peraturan permainan olahraga tradisional Sanjasio}

Peraturan permainan olahraga tradisional Sanjasio, apabila pemain melakukan lompatan menyentuh pinggir lubang atau tidak tepat pada lubang, maka lompatan tersebut dianggap tidak sah atau up, Maka harus melakukan lompatan kembali sebanyak 3 kali, dengan ketentuan pemain tersebut mengambil posisi paling belakang Teman satu regu. Dalam permainan olahraga tradisional Sanjasio, Pemain tidak menggunakan alas kaki. Pemain bejumlah 18 orang, masingmasing regu terdiri dari 9 orang pemain, kemuadian wasit berjumlah 5 orang. Durasi dalam permainan olahraga tradisional Sanjasio selama 15 menit. Penentuan menang dan tidaknya ditentukan dari jumlah batu poin yang dimasukan kekotak poin.

Ukuran lapangan olahraga tradisional Sanjasio

$>$ Luas lapangan: 47.25 meter

$>$ Panjang lapangan: 15 meter

$>$ Lebar lapangan: 3.15 meter

Ukuran papan start : Panjang $50 \mathrm{~cm}$, Lebar $15 \mathrm{~cm}$

> Ukuran lubang lompatan : $60 \mathrm{~cm}$, kedalaman lobang $5 \mathrm{~cm}$

$>$ Jarak antar lubang lompatan: 1 meter

> Jarak dari papan start ke lubang: $80 \mathrm{~cm}$

> Ukuran kotak poin : Panjang $20 \mathrm{~cm}$, Lebar $20 \mathrm{~cm}$

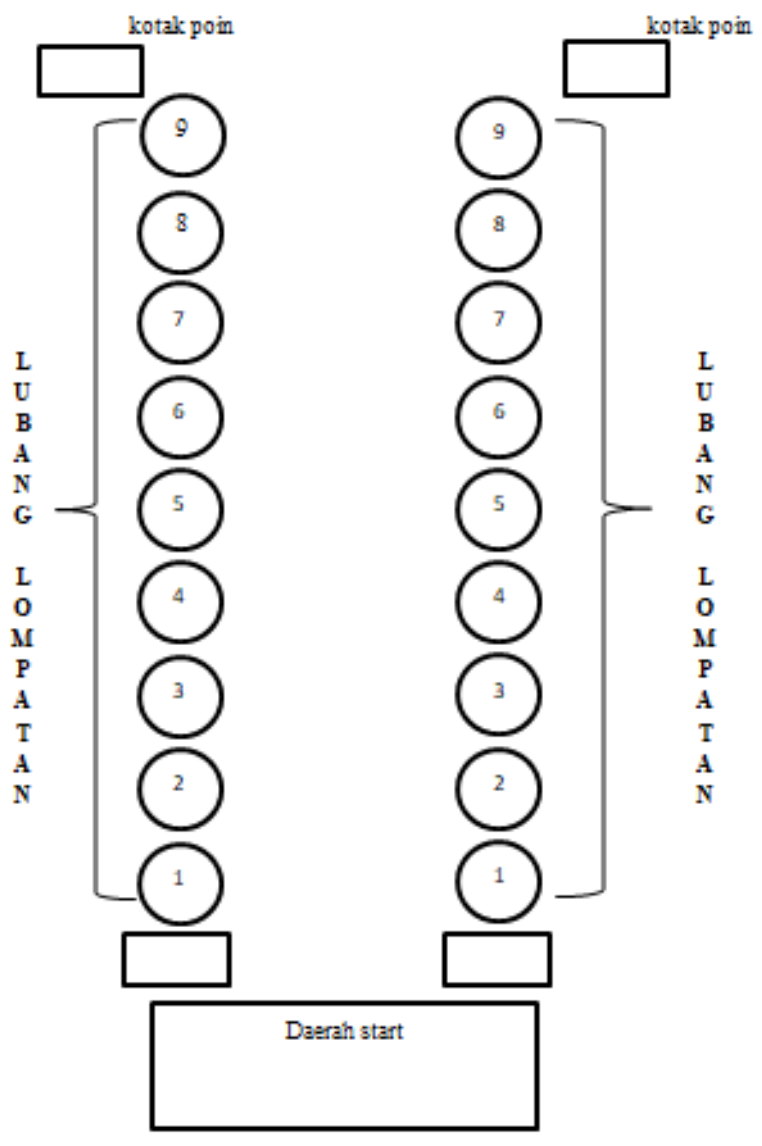

Gambar: 1. Lapangan permainan Sanjasio 


\section{Alat yang digunakan dalam permainan olahraga tradisional sanjasio}

1. Kotak poin sebanyak 2 buah

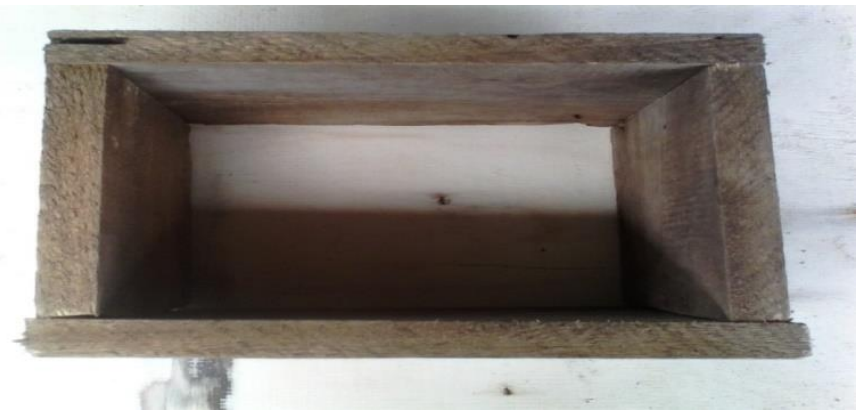

Gambar: 2. Kotak poin (Dokumentasi Pribadi)

Kotak poin terbuat dari papan yang berukuran, panjang $20 \mathrm{~cm}$, dan lebar $10 \mathrm{~cm}$, kotak poin digunakan untuk meletakkan batu ketika permain telah menyelesaikan lompatan terakhir, kemudian ketika permainan selesai dimainkan mulailah wasit menghitung berapa jumlah batu yang ada dikotak poin, dan dari situlah ditentukan menang dan tidaknya suatu permainan.

2. Papan star

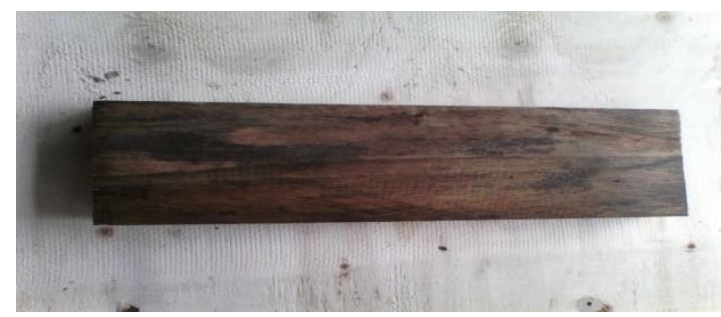

Gambar: 3. Papan Start (Dokumentasi Pribadi)

Papan start berukuran $15 \mathrm{~cm}$ lebar, dan panjang $50 \mathrm{~cm}$. papan start digunakan sebagai awal permulaan loncatan atau sebagai tumpuan. Apabila pemain melakukan permulaan loncatan melewati papan start, berarti loncatan dianggap tdk sah atau up, jdi pemain harus mengulangi loncatan kembali.

3. Gendang

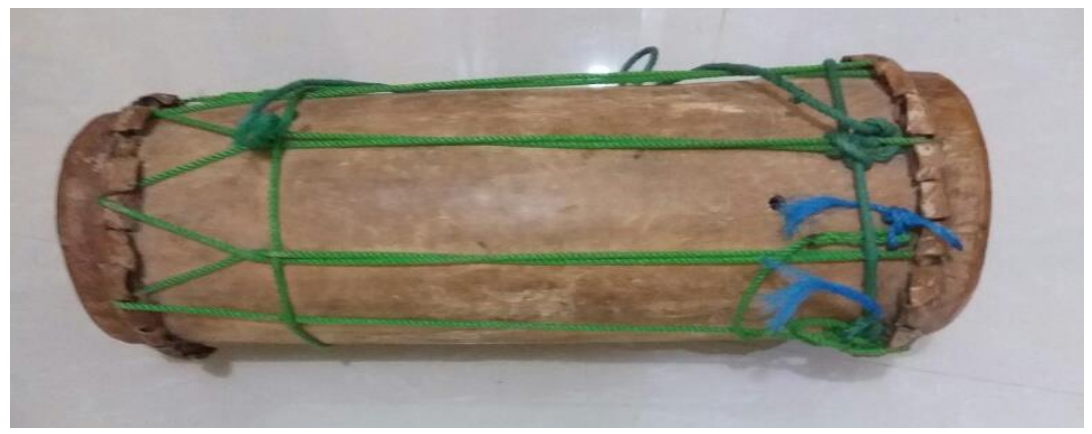

Gambar 4 Gendang (Dokumentasi Pribadi)

Penggunaan gendang adalah untuk membangkitkat semangat para pemain olahraga tradisional Sanjasio. Kemudian gendang dimainkan dari awal permainan sampai permainan selesai dimainkan. 
4. Lalove

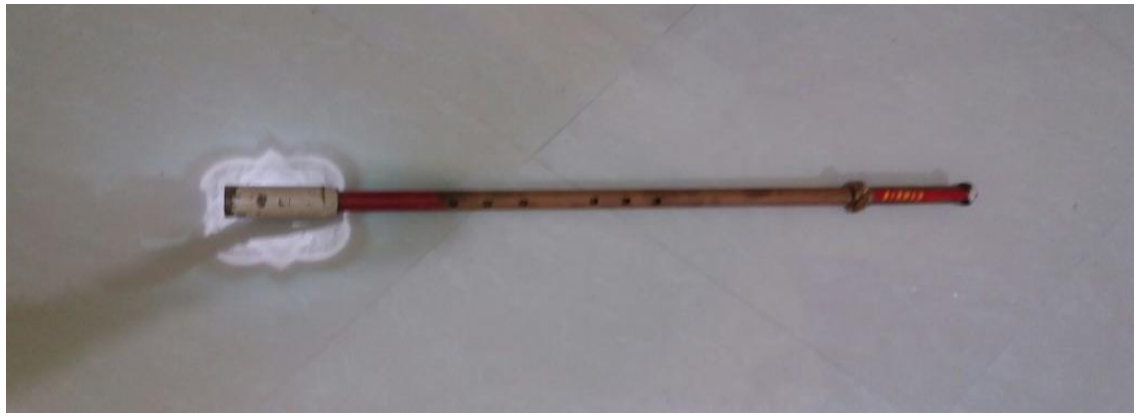

Gambar 5 Lalove (Dokumentasi Pribadi)

Lalove adalah salah satu alat musik tradisional tanah Kaili. penggunaan Lalove Sama seperti gendang, yaitu untuk membangkitkan semangat para pemain olahraga tradisional Sanjasio, Lalove dimaikan dari awal permainan, sampai permainan selesai dimainkan.

5. Batu sebesar jempol kaki

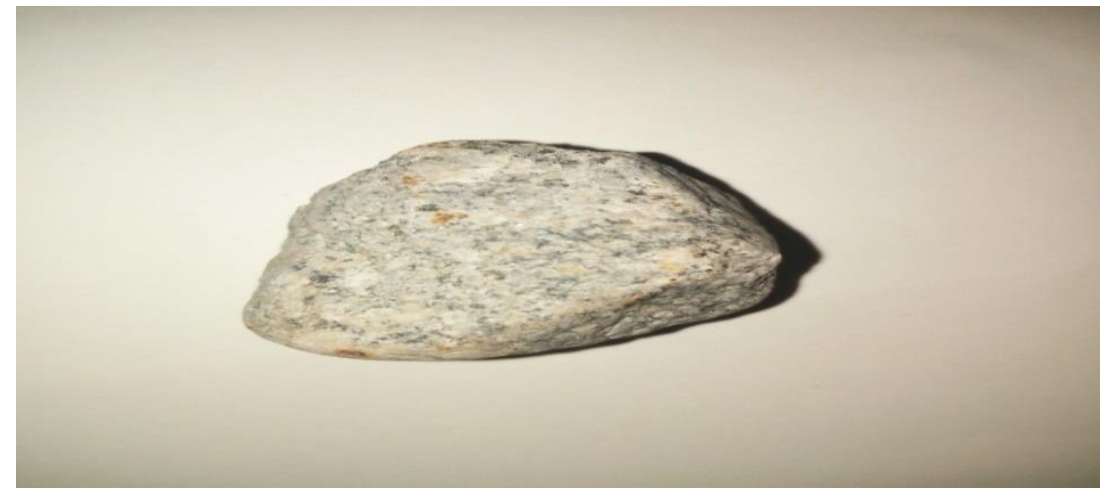

Gambar 6 Batu Poin (Dokumentasi Pribadi)

Batu digunakan sebagai simbol poin, jadi jumlah poin tergantung dari batu yang kita masukkan ke kotak poin.

6. Sumbu kompor

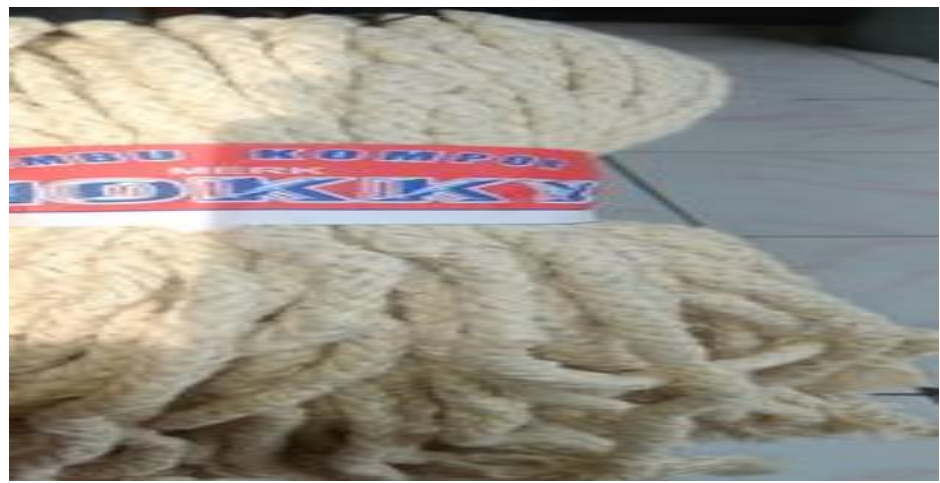

Gambar 7 Sumbu kompor 
Creating Productive and Upcoming Sport Education Profesional Hmzanwadi University

Vol.3, No.2, Desember 2020, Hal. 71-80

e-ISSN 2614-8781

Sumbu kompor digunakan untuk membuat api dilingkaran loncatan. api digunakan agar tidak menghilangkan tradisi yang suda ada sejak dulu oleh suku Kaili Njedu.

\section{Nyanyian dalam olahraga tradisional Sanjasio}

Olahraga tradisional Sanjasio sangat memegang erat tradisi Kaili, dimana sebelum olahraga tradisional Sanjasio dimainkan ada nyanyian yang menggambarkan bagaimana bentuk perlawanan Suku Kaili Njedu terhadap tentara Balangingi

\section{Respon masyarakat terhadap olahraga tradisional Sanjasio}

Respon masyarakat sangat baik, karena bagaimana kita masyarakat Sindue melestarikan budaya Kaili atau olahraga tradisional Sanjasio yang sudah di ambang kepunahan. Dari olahraga ini generasi muda bisa mengetahui bahwa ternyata ada olahraga tradisional asli Tanah Kaili, yang belum dikenal oleh masyarakat umum, terutama masyarakat Sindue sendiri. Jadi kita patut bangga sebagai masyarakat Sindue, karna mempunyai tradisi-tradisi yang masi kental akan budaya Kaili salah satunya adalah olahraga tradisonal Sanjasio itu sendiri.

Pembahasan

Olahraga tradisional Sanjasio adalah bentuk permainan lama oleh Suku Kaili Njedu yang mengutamakan kemampuan fisik, ketangkasan, keseimbangan, kecepatan, ketepatan melakukan loncatan, dan kerjasama tim, makna dari kata Sanjasio adalah Sanja berarti berbaris, dan Sio berarti Sembilan, dikatakan Sanjasio karna masing-masing pemain terdiri dari sembilan orang pemain. olahraga ini biasanya dilakukan pada saat panen telah tiba, dikenal dengan istilah Kailinya Novonju (tradisi sebelum panen) atau Nomparoya (tradisi sesudah panen). olahraga ini bisa dikatakan punah oleh perkembangan zaman, karna kurangnya perhatian dari masyarakat untuk melestarikan olahraga tradisional Sanjasio. Olahraga tradisional Sanjasio ini diangkat kembali oleh pak Lahmudin. L Tindavera pada tanggal 7 Juni 2006, awal mula olahraga tradisional Sanjasio ini tercipta berdasarkan sejarah perlawanan Suku Kaili Njedu melawan tentara Balangingi di Pinggiran Pantai Sindue, adapun tujuan pak Lahmudin mengangkat kembali olahraga tradisional ini adalah untuk melestarikan olahraga tradisional asli Tanah Kaili yang suda punah di Kecamatan Sindue Kabupaten Donggala Provinsi Sulawesi Tengah. Menurut informan olahraga ini bisa dimainkan oleh masyarakat umum, dan adapula batasan usia untuk yang memainkan olahraga ini, yaitu usia 7 sampai 25 tahun, karna olahraga ini menggunakan api, jadi ada tingkatan ketika ingin memainkan olahraga ini, yaitu pada usia 7-12 tahun mereka belum bisa menggunakan api, dikarenakan, mereka harus banyak melakukan latihan terlebih dahulu untuk benar-benar dikatakan bisa melakukan loncatan menggunakan api. Adapun Tujuan dari gerakan olahraga tradisional Sanjasio adalah untuk melatih keseimbangan tubuh, kelincahan, kecepatan, dan ketepatan ketika melakukan loncatan. Dalam sejarah perkembangannya olahraga tradisional Sanjasio di Kecamatan Sindue, telah mengikuti pertandingan ditingkat provinsi Sulawesi tengah:

1. Tahun 2010 ditampilkan di Marjun habi, dan mendapat juara 2

2. Tahun 2012 ditampilkan di STQ dan mendapat juara 2

3. Tahun 2014 ditampilkan di Marjun habi dan mendapat juara 3

Olahraga Sanjasio biasanya dimainkan pada hari-hari tertentu, seperti ulang tahun Kecamatan Sindue dan hari-hari besar lainnya seperti perayaan peringatan hari Kemerdekaan Republik Indonesia. Adapun respon masyarakat sangat baik, karena bagaimana masyarakat 
Creating Productive and Upcoming Sport Education Profesional Hmzanwadi University

Vol.3, No.2, Desember 2020, Hal. 71-80

e-ISSN 2614-8781

Sindue melestarikan budaya Kaili atau olahraga tradisional Sanjasio yang sudah di ambang kepunahan. Dari olahraga ini generasi muda bisa mengetahui bahwa ternyata ada olahraga tradisional asli Tanah Kaili, yang belum dikenal oleh masyarakat umum, terutama masyarakat Sindue sendiri. Jadi kita patut bangga sebagai masyarakat Sindue, karna mempunyai tradisitradisi yang masi kental akan budaya Kaili salah satunya adalah olahraga tradisonal Sanjasio itu sendiri.

\section{Simpulan}

Olahraga tradisional adalah bentuk kebiasaan masyarakat tertentu, yang memiliki ciri khas keaslian daerah serta disesuaikan dengan tradisi budaya setempat. Olahraga tradisional sepatutnya diangakat kembali agar tidak punah oleh perkembangan zaman. Salah satunya adalah olahraga tradisional Sanjasio yang dimiliki oleh suku kaili Njedu tepatnya di Kecamatan Sindue Kabupaten Donggala Provinsi Sulawesi Tengah, olahraga Sanjasio adalah bentuk olahraga tempo dulu oleh masyarakat Suku kaili Njedu disaat panen telah tiba dikenal dengan istilah kailinya Novonju atau Nomparoya. Pemain Sanjasio berjumlah 18 orang, masing-masing regu terdiri dari 9 orang pemain, dan wasit berjumlah 5 orang, pemain musik berjumlah 2 orang , yaitu pemain Gendang dan Lalove, sebelum permainan dimulai ada nyanyian tradisi Kaili sekaligus pemanasan, Durasi permainan selama 15 menit., menang tidaknya suatu permainan ditentukan dari jumlah batu yang dimasukan ke kotak poin.

\section{Daftar Pustaka}

Ajun Khamdani. 2010. Olahraga Tradisional Indonesia. Klaten: PT. Mancanan Jaya Cemerlang. Ari kunto, S. (2002). Prosedur Penelitian. Jakarta : PT. Rineka Cipta.

Afrian, H. (2019). Modifikasi Peraturan Permainan Tradisional Presean Tingkat Sekolah Dasar (SD). Jurnal Porkes, 1(2), 48-51.

Afrian, H. (2019). Modifikasi Peraturan Permainan Tradisional Presean Tingkat Sekolah Dasar (SD). Jurnal Porkes, 1(2), 48-51.

Bambang Laksono, dkk. (2012). Kumpulan Permainan Rakyat Olahraga Tradisional. Jakarta: Kementrian Pemuda dan Olahraga Republik Indonesia.

Bungin, Burhan. 2001. Metodologi Penelitian Sosial. Surabaya: Airlangga University Press.

Desi Susiani. (2009). Profil Fisik Alet Taekwondo Sleman pada Porprov DIY 2009. Skripsi.

Yogyakarta: Fakultas Ilmu Keolahragaan Universitas Negeri Yogyakarta

Eka Septiani. (2013). Profil Kondisi Fisik Anggota Unit Kegiatan Mahasiswa Baseball Putra

Universitas Negeri Yogyakarta. Skripsi. Yogyakarta: Fakultas Ilmu Keolahragaan

Universitas Negeri Yogyakarta.

Eri pratiknyo dw dan erni suharini, (2003). Metode penelitian. Suatu pendkatan praktis

Semarang: Uneversitas Negeri Semarang

Esterbeg, kristin G; Qualitative methods in social research, Mc graw hill, New york, 2002

Indra Safari. 2010. Analisis Unsur Fisik Dominan pada Olahraga Tradisional. Jurnal Kependidikan. 40 (2):157-164.

Ismail, M. H., Suryadi, L. E., \& Nopiana, R. (2019). Pengaruh Permainan Tradisional Engklek Terhadap Peningkatan Kemampuan Lompat Jauh Tanpa Awalan Pada Siswa Kelas 5. Jurnal Porkes, 1(2), 44-47.

Lahmudin. (2006). Permainan sanjasio:sindue induk

Miles maetheaw B, dan Huberman A, Michael (terjemahan Tjetjep Roehandi, 1992).Analisis Data Kualitatif. UI Prees. Jakarta 
Creating Productive and Upcoming Sport Education Profesional Hmzanwadi University Vol.3, No.2, Desember 2020, Hal. 71-80

e-ISSN 2614-8781

Moleong, J.Lexy. (2012). Metodologi penelitian kualitatif. Bandung: PT. Remaja Rosda Karya Bandung

Rahma Azahari. Abd. (2016). Pengembangan model revitalisasi olahraga tradisional menjadi sport for all pada masyarakat suku dayakdari perspektif fenomenologi [Online], Vol 8 (2) Tersedia. Http: konstruktivisme.unisbablitar.ejournal.web.id. [4 Februari 2018].

Suryansah, S., Dinata, K., \& Daniyantara, D. (2019). MODEL PENGEMBANGAN PERMAINAN PERESEAN DALAM MENINGKATKAN MINAT OLAHRAGA TRADISIONAL PADA SISWA KELAS X DI SMA NEGERI 1 PRAYA TIMUR. Jp. jok (Jurnal Pendidikan Jasmani, Olahraga dan Kesehatan), 3(1), 27-42.

Suryansah, S. (2020). Kegiatan Latihan Keseimbangan Dan Konsentrasi Pemula Karate Menggunakan Permainan Tradisional. JURNAL ABDI POPULIKA, 1(2), 44-53.

Sugiyono. (2016). Metode Penelitian Pendidikan. Bandung: alfabeta

Sugiyono. (2013). Metode penelitian kuantitatif kualitatif dan $R \& D$. Bandung: Alfabeta Sugiyono. (2010). Metode penelitian kuantitatif, kualitatif, dan $R \& D$. Bandung: Alfabeta Sugiyono. (2008). Metode Penelitian Kuantitatif Kualitatif dan $R \& D$. Bandung : Alfabeta.

Suharsimi Arikunto. (2002). Prosedur Penelitian Suatu Pendekatan Praktek.Jakarta: Penerbit Rineka Cipta

Sutrisno Hadi. (2004). Metodologi Research Jilid 1.Yogyakarta : Penerbit Andi Yogya Te Bu. 2011. Dilemma of study on Chinese National Traditional Sports Culture and the Selection of Paths. Journal Social Sports and Management.7 (1):115-121. 